Wailbrai : 67.4-84.3 (mean 73.5); Burera: 64.2 80.0 (mean 70.9). Obviously, while the ranges are wider, some of these means are very close to the northern Queensland mean, and many of these heads are much more brachycephalic. Indeed, if the dwarf were eliminated the Monamona mean would not differ materially from any other aboriginal mean. One further point : while Dr. Gates tacitly endorses my view ${ }^{9}$ that head-length and head-breadth vary independently, he evidently did not read far enough to gain some insight on brachycephaly. It is true that, ceteris paribus, head-length is determined genetically (subject to some environmental modification as Boas has shown) in fully developed adults, but it is not necessary to invoke any involved genetic mechanism to explain short-headedness in pygmoid people. These are in an infantile state of development and their heads betray the characteristically infantile brachycephaly.

There is no space here to mention a number of factual errors in Dr. Gates's papers, and certainly no necessity to follow his excursions into archæology and geology. Perhaps it is best to conclude with one's own views, based upon the examination of several hundreds of aborigines in various, widely separated, parts of the continent.

Aborigines betray a fairly wide range of physical variation, but such variation is intratribal, not intertribal. That is, the tribes, practically anywhere, show a parallelism in the range of variation, and the means for the tribes come out remarkably close to each other. This implies a high level of physical homogeneity throughout the continent-all the more singular because the maximum aboriginal population is said never to have exceeded some 300,000 and such a small number, dispersed in small inbreeding groups throughout an area of nearly $3,000,000$ square miles, surely had little chance of achieving such uniformity by interbreeding. On the contrary, genetic drift in what were practically isolates would be expected to produce a wide physical diversity from one end of the continent to the other. The fact that what diversity occurs is but slight points to $a_{4}$ few tentative conclusions. It suggests first that the initial aboriginal landing comprised only a relatively small party bringing only a limited genetic pool. The second conclusion is that there had been a minimum of subsequent admixture with other peoples before the advent of Europeans. Thirdly, the aborigines could have occupied Australia for only a relatively short period-certainly not long enough to produce any obvious physical differences from place to place. This last is in harmony with their uniformly mesolithic culture $^{5}$ and with carbon-14 datings which, so far at least, cannot certainly be associated with human occupation beyond about 6,000 B.c.

${ }^{1}$ Gates, R. Ruggles, Act. Gen. Med. Gem., 9, 7 (1960).

${ }^{2}$ Gates, R. Ruggles, Z. Morph. Anthrop., 50, 150 (1960).

${ }^{3}$ Abbie, A. A., and Adey, W. R., Amer. J. Phys. Anthrop., 11, 339 (1953).

Abbie, A. A., The Leech, 28, 120 (1958).

5 Abbie, A. A., Oceania, 22, 91 (1951).

- Birdsell, J. B., Cold Spring Harbor Symp. Quant. Biol., 15, 259 (1950).

7 Tindale, N. B., and Birdsell, J. B., Rec. S. Aust. Mus., 7, 1 (1941).

${ }^{8}$ Basedow, H., "The Australian Aboriginal" (Preece, Adclaide, 1925).

Abbie, A. A., J. Anat. (Lond.), 81, 233 (1947).

${ }^{10}$ Abbie, A. A., Oceania, 27, 220 (1957).

11 Abbie, A. A., and Adey, W. R., Oceania, 25, 198 (1955).

\title{
HERBICIDES AND THE SOIL
}

$\mathrm{M}$ ODERN techniques of herbicidal applications fall into two groups. Direct application may be made to the soil followed by absorption through the roots or applications may be made to the foliage where entry is largely dependent on penetration through the leaves. This distinction is not, however, clear cut, since with foliar applications some of the droplets will fall on the ground while some of the compound may be washed off the leaves by rain. Thus for both types of technique it is of major importance to ascertain how long individual compounds persist in the soil, what are the physical or biological factors which cause their removal or decomposition and what are the effects on the fauna and flora of the soil. It was against this background that the British Weed Control Council organized a symposium on "Herbicides and the Soil", which was held in the Clarendon Laboratory, University of Oxford, on April 7.

The opening speaker was Prof. L. J. Audus (Bedford College, London) on "Microbiological Breakdown of Herbicides in Soils". Before direct investigations on the rate of decomposition of herbicides was undertaken it had been observed in the field that the persistence of some, as judged by the effects on plant growth, was minimal when the soil was moist and warm, conditions generally accepted as being favourable to micro-organisms. Since these conditions could also favour chemical decomposition it was difficult to separate the operative factors except in the laboratory.
The fact that breakdown in the soil was largely arrested by autoclaving and that the addition of compounds known to be inhibitory to micro-organisms also slowed down the rate of decomposition pointed to the conclusion that micro-organisms were involved.

If micro-organisms are responsible for the breakdown of a herbicide, then the addition of such a compound to the soil under constant and favourable conditions will not result in immediate breakdown, as in a chemical process, but there will be a lag phase while there is a build-up of the population of the effective organisms.

At Bedford College the perfusion technique has been employed to study the breakdown of substituted phenoxyacetic acids and in every case the existence of a lag phase has been demonstrated. It has also been established that once decomposition has taken place in a soil, then the speed of breakdown of a further addition of the chemical is increased.

In 1950, Audus isolated an organism of the Bacterium globiforme group which was able to multiply on an agar medium containing 2,4-dichlorophenoxyacetic acid as the sole source of carbon. This organism, when added to garden soil, immediately accelerated the rate of breakdown of 2,4-dichlorophenoxyacetic acid. Since this original isolation, it has been found that a wide range of bacteria, actinomycetes and fungi are capable of using herbicides as their only source of carbon. 
For the substituted phenoxyacetic acids there is no clear correlation between the duration of the lag phase and chemical structure, but it is apparent that the position on the ring of a single chlorine substituent is important ; for example, a change of the substituent from the 4 to the 2 position makes the compound much more resistant to attack. In di- and trisubstituted compounds the presence of a 4-chloro substitution overrides the influence of other substitutions. N. Brownbridge, however, sought to discover whether ease of breakdown was linked with the level of phytotoxicity of the chemical to higher plants as judged by the concentration necessary to reduce the rate of growth of cress roots by 50 per cent. Excluding the value for 2-chloro-4 methylphenoxyacetic acid, there was a highly significant inverse correlation. The position of 2-chloro-4 methylphenoxyacetic acid was anomalous ; the lag phase was far too long, judged on the degree of phytotoxicity.

If a soil was first treated with 2-chloro-4 methyl phenoxyacetic acid and another substituted phenoxyacetic acid was then added, the breakdown of the second compound was rapid ; for example, even after prolonged perfusion 2,4,5-trichlorophenoxyacetic acid is very slowly decomposed but 2-chloro-4 methylphenoxyacetic acid treated soil can break down 2,4,5-trichlorophenoxyacetic acid more readily. Soils first treated with other phenoxyacetic acids did not gain the power to attack other compounds to the same extent.

Prof. W. W. Fletcher (West of Scotland Agricultural College, Glasgow) spoke on the "Effects of Herbicides on Soil Micro-organisms" and emphasized that although a few chemicals did reduce the population of the soil micro-organisms, the net effect was ultimately one of stimulation as one or more species became adapted to use the herbicide as a substrate. Organisms responsible for nitrification and nodulation appear to be more sensitive than other bacteria to a wide range of herbicides including sodium chlorate, 2-chloro-N,N-diethylacetamide and 2-chloro-N,Ndiallylacetamide when applied at normal rates in the field. There is a general agreement that 2-chloro-4 methylphenoxyacetic acid, 2,4-dichlorophenoxyacetic acid and 2,4,5-trichlorophenoxyacetic acid at the normal rates employed in agriculture have no adverse effects on the total number of microorganisms, and it would appear that 2,2-dichloropropionic acid augments rather than depresses the general soil population.

The species of one genus may vary greatly in their response to chemicals. For example, 3,5-dinitro-ocresol inhibited Rhizobium lupini at 198 p.p.m., whereas $R$. meliloti and $R$. leguminosarum required 1,980 p.p.m. for inhibition.

Dr. G. S. Hartley (Chesterford Park Research Station) spoke on the "Physico-chemical Aspect; of the Availability of Herbicides in Soils". Beginning with a simple theoretical model, Dr. Hartley defined his problem within the system-soil particulate structure-air-water-herbicide.

In the simplest case, if the water content is at 'field capacity' and a non-volatile water-soluble herbicide is applied uniformly to the soil surface, then as long as the system remains undisturbed the herbicide can move only by diffusion in the water phase. The rate of this movement can be calculated and for molecules of the size of herbicides 1 per cent of the applied chemical will move rather more than $2 \mathrm{ft}$. downward in three years. The presence of solid matter in such a system as well as air locks reduces the 'expected' rate of diffusion. When corrections for these obstacles are applied to the theoretical figure it is apparent that 1 per cent of an applied soluble herbicide might take twelve years to reach a depth of $2 \mathrm{ft}$. It must therefore be concluded that the downward movement of herbicides in the field is not by diffusion alone.

Again in an ideal uniform system, and assuming field capacity to be 25 per cent v/v, $10 \mathrm{~cm}$. of rainfall would sweep a readily soluble herbicide to a depth of $40 \mathrm{~cm}$., where it would be localized in a narrow band. In the field where a soil is heterogeneous the herbicide will move unevenly downwards. This unevenness is especially marked if rainfall is heavy, when the herbicide is washed down the larger channels or cracks in the soil. Dr. Hartley suggested that the difference between observed and calculated rates of movement could be largely explained in terms of the heterogeneity of the soil system.

Attempts to measure the rates of movement of herbicides downwards have all departed from field conditions by applying 'rainfall' at extremely heavy rates and thereby introduced large errors. Relatively insoluble herbicides go into solution slowly; for example, a sphere of trichloroacetic acid $5 \mu$ in radius might dissolve in seconds, whereas a sphere of simazine of identical size would take $30 \mathrm{hr}$. Therefore, unless rainfall is prolonged, the more insoluble sub. stances may resist leaching due to their failure to go into solution, although sufficient water in toto may be applied to take all herbicides into solution.

Upward movement of a herbicide in the soil is induced by the evaporation of the soil water. Evaporation will take place almost entirely from the surface of a wet soil, but as the capillary conduction system breaks down the rate of loss of water falls sharply. This upward movement of herbicides will accentuate a tendency for herbicides to be concentrated near the surface of the soil in dry weather.

Even at a rate of application of 100 gal./acre the sorption of a spray solution into the capillaries of a dry soil lump can be quite pronounced and subsequent release of the chemical from such places is by the slow process of diffusion. The only way to counter this appears to be spray when the soil is wet. The development of granular herbicides promises to overcome some of these difficulties since the amount of rainfall necessary to extract the herbicide from the granule is probably sufficient to ensure thorough wetting of the easily accessible sites in the soil before the granules release their active content. A simple experiment using a freely soluble dye added to plaster-of-paris columns showed that the extraction of the dye passing through the columns was far more complete and far quicker if the columns were first wetted with water.

Dr. W. van der Zweep (Wageningen) contributed to the meeting a consideration of the practical use of herbicides in relation to their persistence in the soil. Frequently, the rate of application and the chemical used are determined by the persistence that can be tolerated by the following crops. In certain cases control and not eradication of weeds is a penalty that must be accepted if a following crop is to be safeguarded. Mechanical incorporation of a chemical into the soil increases the persistence if the chemical has a high vapour pressure. In other cases incorporation improves the effectiveness of the chemical and 
also assists subsequent breakdown so that a following crop may be sown with increased safety. Persistence may be varied according to the formulation of the chemical used. Dr. van der Zweep brought his contribution to an end by appealing for information on the half-life of herbicides, a half-life determined in the first instance in standardized laboratory tests.
Such a system could be extended to field studies where tho variation would be apparent and could bo measured.

The full proceedings of the meeting together with reports of the discussion which followed each paper will be published by Blackwell Scientific Publications, Ltd., later this year.

\section{COLLOID AND POLYMER SCIENCE}

$\mathrm{C}$ ONTINUING earlier seminars ${ }^{1}$ in the Dopart1 ment of Chemistry of University College, London, nine lectures were given during February 25-March 18. Drs. C. H. Barnford and J. A. Kitchener summarized work (some of which has been published ${ }^{2,3}$ ) on calculation of free-radical reactivity and stability of colloidal model suspensions. Prof. J. A. V. Butler discussed some flow propertics of dilute solutions of deoxyribonueleic acid in $0.2 \mathrm{~N}$ sodium chloride, the rate of shear being varied in the range $0 \cdot 5-30,000$ sec. $^{-1}$. At the high rate of shear no permanent change of the soluto occurred, but some disentangling of networks. Using the theories of Kuhn and Kuhn ${ }^{4}$ and Cerf's, for the results obtained at low rate of shear, it appears that the deoxyribonucleic acid molocule is somewhat flexible. Dr. P. W. Allen described the grafting of mothylmethacrylate polymers on natural rubber latex using hydrogen peroxide, together with a polyethylenc amine, as initiators. Under these conditions the graft co-polymer is mainly formed on tho surface of the latex. If oil-soluble initiators are used, polymerization of methylmethacrylate occurs insido the latex. Dr. C. Robinson reviewed recent work ${ }^{6}$ on liquid crystals of synthetic polypeptide and described a now effect : if a concentrated solution of poly- $\gamma$ ethyl-L-glutamate is illuminated with white light, brilliant iridescent colours are reflected. This is explained as an optical analogue of an X-ray powder diagram. There aro indications that deoxyribonucleic acid solutions can also form liquid-crystals.

Prof. A. Katchalsky discussed the application of the thermodynamics of irreversible processes? to the study of colloid-chemical phenomena. The treatment of entropy production as the sum of the products of generalized forces and conjugated flows was outlinod. Sufficiently slow flows are linearly dopendent on all the forces operative in the system, through a set of phenomenological equations, the coefficients of which obey Onsager's law and constitute a symmetrical matrix. The phenomenological equations provide a convenient formal framework for the description of electrokinetic phenomena ${ }^{9}$, and permit the establishment of the classical Saxen rolations on a thermodynarnic basis. A similar treatment ${ }^{10}$ of polyelectrolyte solutions leads to new correlations between transport phenomena, such as diffusion, sedimentation and conductance. The thermodynamic approach is useful in tho analysis of membrane permeability ${ }^{11-13}$ : contradictions inherent in the conventional equations do not occur and a consistent set of equations is obtained, suitable for the description of the transport of electrolytes and non-olectrolytes through membranes ${ }^{14}$. The coefficients of these equations were transcribed in torms of frictional forces and distribution coefficients, which characterize the interaction of the permeant solutes with the membrane. In the last lecture, Prof. Katchalsky discussed some fundamentals of mechanochemistry ${ }^{15}$.

1 Nature, 182, $762(1958)$.

${ }^{2}$ Bamford, C. H., Jenkins, A. D., and Johnston, R., Trans. Faraday Soc., 55, $418(1959)$.

${ }^{3}$ Schenkel, J. H., and Kitchener, J. A., Trans. Faraday Soc., 56, 161

(1960).
'Kuhn, W., Kuhn, H., and Buchner, P., Ergeb. exakt. Naturw., 25, 1 (1951).

${ }^{5}$ C.R. Acad. Sci, Paris, 243, 1875 (1956); 244, 456 (1957).

${ }^{6}$ Robinson, C., Trans. Faraday Soc., 52, 571 (1956). Robinson, C., and Ward, J. C., Nature, 180, 1183 (1957). Robinson, C., F'araday Soc, Discussions, 25, 19 (1958).

7 Sec Prigogine, I., "Etude thermodynamique des phénomènes irreversibles" (Desoer, Liège, 1947). de Groot, s. R., "Thermodynamics of Irreversible Processes" (North Holland Pub. Co., Amsterdam, 1951).

${ }^{8}$ Onsager, L., Phys. Ren., 37, 405 (1930); 38, 2265 (1931).

Mazur, P., and Overbeek, I. F., Rec. Trav. Chim. Pays-Bas, 70, 83 (1951).

${ }^{10}$ Katchalsky, A., Alexandrovith, Z,, and Kedem, O., "Adv. Chem. Phys." (in the press).

11 Staverman, A. J., Trans. Faraday Soc., 48, 176 (1952).

${ }_{12}$ Kirkwood, W., in "Ion Transport across Membranes", 119 (Acad. Press, New York, 1954).

13 Spiegler, K. S., Trans. Faraday Soc., 54, 1409 (1958).

14 Kedem, O., and Katchalsky, A., Biochim. Biophys. Acta, 27, 229 (1958).

${ }^{16}$ Katchalsky, A., Lifson, S., Michaeli, I., and Z,wick, M., "Size and Shape Changes in Contractile Polymers" (Pergamon Press, London: New York) (in the press).

\section{EFFECTIVENESS IN INDUSTRY}

HE presidential addross of Mr. W. E. Bargett to the Institution of Metallurgists, though specifically directed to that profession, had much of direct interest for other technologies. In discussing the training of both graduates and juniors he pointed out the necessity of realizing that the former, though 'oducated', have still to receive a 'training' oven if during this period they can give little immediate return for their salaries. Equally, "the inefficient utilization of junior people's time is out of kecping with the demands of industry for greater numbers of well-qualified technologists and must be eliminated through sheer economie necessity". It is a general experience that a bright junior is quickly frustrated when called upon to do repetitive work which provides little experionce and makes no particular intellectual demand. The interesting suggestion was made that a solution of this problem might be found by employing older people who may have had no special training, but who have sufficient intelligence to learn all that is required to carry out specific operations, appreciating not only what to do but also why it is done in a certain way. Experience has shown that there is no difficulty in filling 